\title{
Raising Knowledge, Attitude Of Specific Education's Students Toward Vital Signs: An Intervention Study
}

\author{
Dr. Samia M. Abd El-mouty* \& Dr. Samar Elhoseini Abd-Elraouf** \\ *Lecturer of Community Health Nursing, Mansoura University, Egypt \\ ** Associate professor of Community Health Nursing, Mansoura University, Egypt
}

\begin{abstract}
:
Background: Faculty of Specific Education's students program is consider to providing direct experience and a chance to apply newly assimilated skills and knowledge and as teachers in a position to observe on normal and abnormal conditions of schoolchildren because they are able to observe and monitor the students in their classroom each day. Aim of this study is to raise knowledge, attitude of Specific Education's students toward measuring vital signs. Method: A quasi-experimental design was used to conduct the study that included regularly attending fourth year students of the Division of Home Economics, Faculty of Specific Education, Mansoura University. The data were collected using four tools. Result: after implementation of training sessions, there were increases in the posttest mean score of students' knowledge about temperature, pulse, respiration and blood pressure, as they were $2.65 \pm 0.48,2.54 \pm 0.5,2.64 \pm 48$ and $2.38 \pm 0.69$ respectively. The percentage of proper measuring for pulse, respiration and blood pressure ranged from (58.7\% to 66.3\%) in post test two. Posttest for students' attitude toward training on measuring vital signs was most $198.9 \%$ and 90.2\%) of them respectively, stating that there are importance and benefits from training on measuring vital signs. Conclusion: There were significant improvements in students' knowledge, practice and attitude related to vital signs after implementation of training sessions $(P=0.000)$.
\end{abstract}

Keywords: Knowledge, Attitude, Vital signs, Intervention, Education's students

\section{Introduction}

Today, teacher's role is in planning, organizing and implementing an appropriate instructional program in a learning environment that guides and encourages students to develop and fulfill their academic potential ${ }^{(1)}$. Mckenzie,(2005) ${ }^{(2)}$. Williamson County School District, $\left(2009^{(3)}\right.$ demonstrated that teacher work in partnership with other school personnel, parents and a variety of community resources for the purpose of improving the overall quality of student outcomes, counsels students for the purpose of improving performance, health status, problem solving techniques and a variety of personal issues. In addition to, monitors students in a variety of educational environments (e.g. classroom, playground, field trips, nap times, etc.), reports incidents (e.g., suspected child sickness, suspected child abuse, substance abuse, and fights etc.) for the purpose of maintaining personal safety of students, providing a positive learning environment and school board policies. Williamson County School District, $(2010){ }^{(4)}$ added that teachers implement health and safety procedures and administer with the school health team first aid and assistance to medically fragile children for the purpose of providing appropriate care for children as assigned.

A key element of good first assessment is assessing and monitoring vital signs. It consists of taking a series of simple measurements that provide data about a body is functioning. These measurements can help reveal how sick or hurt a person is and, when taken over time, whether he/she is getting better or worse. While the full meaning of these measurements might elude the lay provider, a carefully documented series of vitals can be very supporter to the health-care professionals who will eventually take over the care of sick or hurt persons.

Temperature, heart/pulse rate, respiratory rate and blood pressure are vital signs components. It can be useful even to first aid providers with limited medical training. Sets of vitals that are outside normal ranges typically indicate the need for some treatment or possible evacuation to a higher level of care ${ }^{(5,6)}$. Vital signs are showing how well the vital organs of the body, such as the heart and lungs are working. Vitals should be taken on a regular basis: this helps to know what is normal for the person so that can monitor changes and recognize them as signs or symptoms of illness ${ }^{(7)}$.

Measurements of vital signs provide valuable and fundamental information about a person's condition for early care in emergency situations and basic life support (BLS) to save lives and prevent sequels ${ }^{(8,9)}$. The assessment, measurement and monitoring of vital signs are important basic skills for all working with children, this includes, schools' teachers ${ }^{(5)}$.

Faculty of Specific Education is working to achieve the following objectives: prepare for the specific teacher and specialist in different educational levels and his/her professional preparation in a way that enables her skillful practices to match the labor market changes ${ }^{(10,11)}$. Faculties of Specific Education students' 
practicum provide the experience of working collaboratively in-school placements that are supported by coursework and school/community partnerships. Much of the curriculum for all pre-service programs of the Faculty of Specific Education is linked to practicum experiences. In addition to providing direct experience and an opportunity to apply newly acquired skills and knowledge, the practicum placements are a major source of curriculum in the sense that they bring candidates face to face with concrete situations. The underlying assumptions of this approach are that teaching can be considered as a form of problem solving and that teacher candidates learn best within cohesive academic and practical situations that allow them to understand and to master their environment ${ }^{(12,13)}$.

Although, serious illness in childhood is rare occurrence, but accounts for $20 \%$ of childhood deaths. Early recognition and treatment of serious illness is vital if the child is to recover without long-term disability. It is known that vital signs such as heart rate, respiratory rate, temperature, and blood pressure can be used to identify children who are at high risk of serious illness ${ }^{(14)}$.

The tutorial rooms teachers carry heavy responsibility in screening as on average school day, teachers spend more working hours with children than the parents of children. Teachers are also in a position to observe on normal and abnormal conditions of children because they are able to compare the students in their classroom each day ${ }^{(2)}$. So, implementing a training for Faculty of Specific Education's students on measuring vital signs as the initial and fundamental measures in emergency situation, outbreak of the diseases as well as in routine assessment that point out any deviation from normal.

\section{Aim of the study}

The aim of this study is to raise knowledge, attitude of Specific Education's students toward measuring vital signs.

\subsection{Research hypothesis:}

\section{Material and Methods}

- Students of Department of Home Economics, the Faculty of Specific Education, Mansoura University will be knowledgeable, and have positive attitude toward vital signs after the intervention sessions.

- Students of Department of Home Economics, the Faculty of Specific Education, Mansoura University will be able to measure vital signs after the intervention sessions

\subsection{Research design:}

A quasi-experimental design (pre-post tests) was utilized as a research design.

\subsection{Setting:}

The study was conducted at the Faculty of Specific Education, Mansoura University during the academic year 2011-2012.

\subsection{Subjects and sampling}

- Faculty of Specific Education, Mansoura University, divided into three branches; Mansoura, Met-Ghamer and Meniat-El-Naser.

- Division of Home Economics was the only Division in the Faculty of Specific Education that studying the course of Community Health and Nursing at the fourth year.

- All the students of Home Economics Division were females.

- All fourth year students at the Division of Home Economics were 150 students. Regularly attending students were 104 included in this study.

- They were distributed as following: 58 student at Mansoura; 34 student at Met-Ghamer, and 12 student (pilot) at Meniat-El-Naser,.

- A pilot study was carried out on 12 students at the branch of Meniat-El-Naser who were excluded from main sample, so the study was carried out on remaining (92) students.

\subsection{Tools of the study:}

The data were collected using the following tools:

2.5.1 First tool: Self administered structured socio demographic characteristics assessment sheet:

$>$ This tool was developed by the researchers in Arabic language after reviewing the related literature to assess socio-demographic characteristics including; age, residence, and marital status.

2.5.2 Second tool: Self administered structured questionnaire to assess students' knowledge:

$>$ This tool was developed by the researchers in Arabic language after reviewing the related literature to assess students' knowledge about vital signs consisted of (38) questions; (5) open questions ended, and (33) close ended questions, such as; definition, components and normal range of vital signs, equipment required for the measuring and different sites of measuring vital signs. 
$>$ The students' responses were scored $(0)$ for an incorrect or didn't know response; poor $(<50 \%)$ for students' responses less than half of the items; average, $50-<65 \%$ for students' responses half to less than two thirds of the items; and good (65-70\%) for students' responses more than two thirds of the items.

2.5.3 Third tool: Students' attitude assessment scale:

$>$ Students' attitude which consisted of (5) questions; (3) close ended questions and (2) open ended questions, toward the importance of training to measure vital signs in general and specially for teachers, fields and ways that could be beneficial.

2.5.4 Fourth tool: Students' practices observation check list:

$>$ This tool was adopted from Clinical Book of Technical Schools of Nursing ${ }^{(15)}$ to assess the students' practices during measuring vital signs which, consisted of (16) items for measuring temperature, 10) items for measuring pulse, (9) items for measuring respiration and (28) items for measuring blood pressure.

$>$ The students' practices were scored $(0)$ for no practice; improper $(<50 \%)$ for students' practices for less than half of the items; average $(50-<65 \%)$ for students' practices for more than half to less than two thirds of the items; and proper practices (65-70\%) for students' practices for more than two thirds of the items.

\subsection{Method}

\subsubsection{Administrative phase:}

$>$ An approval from the Vice Dean for education and students' affairs, and Dean of Faculty of Specific Education at Mansoura University to implement the study.

$>$ The tools were submitted to a panel of (5) members from different fields (two experts in the field of Community Health Nursing, and three experts in the field of Fundamental of Nursing) for content validity.

$>$ Approval was obtained from the Faculty of Nursing Research Ethics Committee. The tools were anonymous and considered confidential. All students were informed about the study in the beginning of the course.

$>$ Reliability and understanding of the all tools were tested to illicit the required information reasonably well. Unrealistic items were omitted. Thus, no major changes were made to the questionnaire.

$>$ Researchers attending schedule were Saturdays at Met-Ghamer, Sundays at Mansoura and Thursdays at Meniat-El-Naser, duration of the session was one hour for each branch. The study lasted from February till June ( $2^{\text {nd }}$ semester $), 2012$.

\subsubsection{Preparation phase of training sessions:}

The necessary assessment of students' knowledge, practices and attitude was done by using first, second, third and fourth tools; this was done in four days. Analysis of the results, and review of literature to plan the sessions for implementation accordingly to, the following steps:

$>$ Identify knowledge.

$>$ Identify skills.

$>$ Setting objectives.

$>$ Writing content, sessions' plan, and the needed information regarding vital signs.

$>$ Choice of teaching methods that included presentation, group discussion, demonstration and role play.

$>$ Preparation of suitable media which included power point presentation, videos films, handouts, dolls and equipment required for measuring vital signs.

\subsubsection{Implementation phase of training sessions:}

The implementation consisted of a short and repeated sessions for 18-20 students per each session. Five groups of students were formulated.

- In the first didactic session, the researchers presented knowledge about vital signs as; the definition and components of vital signs, aims of measuring vital signs, normal range of vital signs, different sites of measuring vital signs and considerations during the measurement.

- In the second practical session; firstly each group watched video films presented procedure of measuring of vital signs, then each group of five formulated groups was divided into two groups and the researchers demonstrated the procedure of measuring vital signs first on the dolls and second on a volunteer student. Students exchanged roles to re-demonstrate and measure vital signs for each other. The students would also be able to return to the teaching and learning DVDs and handout at any point

- Researchers supplemented coordinator of each branch with equipment of measuring vital signs and video to facilitate further training for each student.

\subsubsection{Evaluation phase of training sessions:}

Evaluation of the effect of implementing the training sessions was carried out as follows: 
- Immediately and one month later after the implementation phase by using the second tool to assess the students' knowledge.

- During students' practicum at preparatory schools (mid of May), every trained student measured vital signs to a school child and a well trained students(6) who were accurately measuring vital signs were selected to assess their peer practices by using the observation chick list in the presence of the researchers by using the fourth tool to assess the students' practice.

- After the conduction of students' practicum by using the third tool to assess the students' attitude.

\subsection{Data analysis:}

The collected data were coded and entered in a data based file using the statistical package for social science (SPSS) version 16. Frequency analysis and manual revision were used to detect any errors. The following statistical measures were utilized:

1. Descriptive measures included: frequencies, percentage, arithmetic mean and standard deviation.

2. Statistical tests including: a Chi square and Paired test were used to compare quantitative and qualitative data.

\section{Results}

Table (1): Distribution of students according to their socio-demographic characteristics $n=92$

\begin{tabular}{|l|l|l|}
\hline Items & No & \% \\
\hline Age $19.85 \pm 1.54$ & \multicolumn{2}{|l|}{} \\
\hline Residence & 63 & 68.5 \\
\hline Urban & 29 & 31.5 \\
\hline Rural & \multicolumn{2}{|l|}{} \\
\hline Marital status & 64 & 69.6 \\
\hline Single & 28 & 30.4 \\
\hline Married &
\end{tabular}

Table (1) shows the distribution of students according to their socio-demographic characteristics. Their mean age was $19.85 \pm 1.54$ years and less than three fourths $(68.5 \% \& 69.6 \%)$ of the students were resident at urban areas and single respectively.

Table (2): Distribution of students according to their knowledge about definition and components of vital signs

\begin{tabular}{|c|c|c|c|c|c|c|c|}
\hline \multirow[b]{3}{*}{ Items } & \multicolumn{4}{|c|}{$\mathrm{n}=92$} & \multirow{2}{*}{\multicolumn{2}{|c|}{ Post test two }} & \multirow{3}{*}{$\begin{array}{l}\text { Chi-Square } \\
\text { ( P-value) }\end{array}$} \\
\hline & \multicolumn{2}{|l|}{ Pre } & \multicolumn{2}{|c|}{ Post test one } & & & \\
\hline & No & $\%$ & No & $\%$ & No & $\%$ & \\
\hline \multicolumn{8}{|c|}{ Definition of vital signs } \\
\hline Didn't know & 45 & 48.9 & 0 & 0 & 0 & 0 & \multirow{4}{*}{$\begin{array}{l}112.562 \\
(0.000)\end{array}$} \\
\hline Poor & 37 & 40.2 & 13 & 14.1 & 25 & 27.2 & \\
\hline Average & 10 & 10.9 & 24 & 26.1 & 30 & 32.6 & \\
\hline Good & 0 & 0 & 55 & 59.8 & 37 & 40.2 & \\
\hline \multicolumn{8}{|c|}{ Components of vital signs } \\
\hline Didn't know & 55 & 59.8 & 0 & 0 & 0 & 0 & \multirow{4}{*}{$\begin{array}{l}127.192 \\
(0.000)\end{array}$} \\
\hline Poor & 33 & 35.9 & 11 & 12.0 & 16 & 17.4 & \\
\hline Average & 4 & 4.3 & 27 & 29.3 & 33 & 35.9 & \\
\hline Good & 0 & .0 & 54 & 58.7 & 43 & 46.7 & \\
\hline
\end{tabular}

Table (2) reveals the distribution of students according to their knowledge about definition and components of vital signs, none of them had good knowledge about the definition and the components of vital signs before the sessions compared to more than half of them $(59.8 \%$ \& $58.7 \%)$ respectively had good knowledge in post test one but these percentaSges decreased in post test two to less than half of them $(40.2 \% \&$ $46.7 \%)$ respectively. There was significant differences between pre, post one and post two sessions $(\mathrm{P}=0.000)$.

Table (3) \& Figure (1): The difference between students' knowledge mean score related to items of vital signs (pre- post one \& post two).

\begin{tabular}{|c|c|c|c|c|c|c|c|c|c|}
\hline \multirow[b]{2}{*}{ Items } & \multicolumn{2}{|l|}{ Pre } & \multicolumn{2}{|c|}{ Post test one } & \multicolumn{2}{|c|}{ Post test two } & \multicolumn{3}{|c|}{ t-test ( P-value) } \\
\hline & Mean & \pm SD & Mean & \pm SD & Mean & \pm SD & Pre- Post & $\begin{array}{l}\text { Pre- Post } \\
\text { two }\end{array}$ & $\begin{array}{l}\text { Post -Post } \\
\text { two }\end{array}$ \\
\hline Body temperature & 1.45 & 0.72 & 2.65 & 0.48 & 2.32 & 0.78 & $\begin{array}{l}-13.427 \\
(.000)\end{array}$ & $\begin{array}{l}-7.855 \\
(.000)\end{array}$ & $\begin{array}{l}3.520 \\
(.001)\end{array}$ \\
\hline Pulse & 1.32 & 0.73 & 2.54 & 0.5 & 2.29 & 0.62 & $\begin{array}{l}-13.367 \\
(.000)\end{array}$ & $\begin{array}{l}-9.829 \\
(.000)\end{array}$ & $\begin{array}{l}3.006 \\
(.003)\end{array}$ \\
\hline Respiration & 1.33 & 0.66 & 2.64 & 0.48 & 2.4 & 0.74 & $\begin{array}{l}-15.360 \\
(.000)\end{array}$ & $\begin{array}{l}-10.359 \\
(.000)\end{array}$ & $\begin{array}{l}2.592 \\
(.010)\end{array}$ \\
\hline Blood pressure & 1.29 & 0.69 & 2.38 & 0.69 & 2.22 & 0.8 & $\begin{array}{l}-10.677 \\
(.000)\end{array}$ & $\begin{array}{l}-8.423 \\
(.000)\end{array}$ & $\begin{array}{l}1.482 \\
(.140)\end{array}$ \\
\hline
\end{tabular}




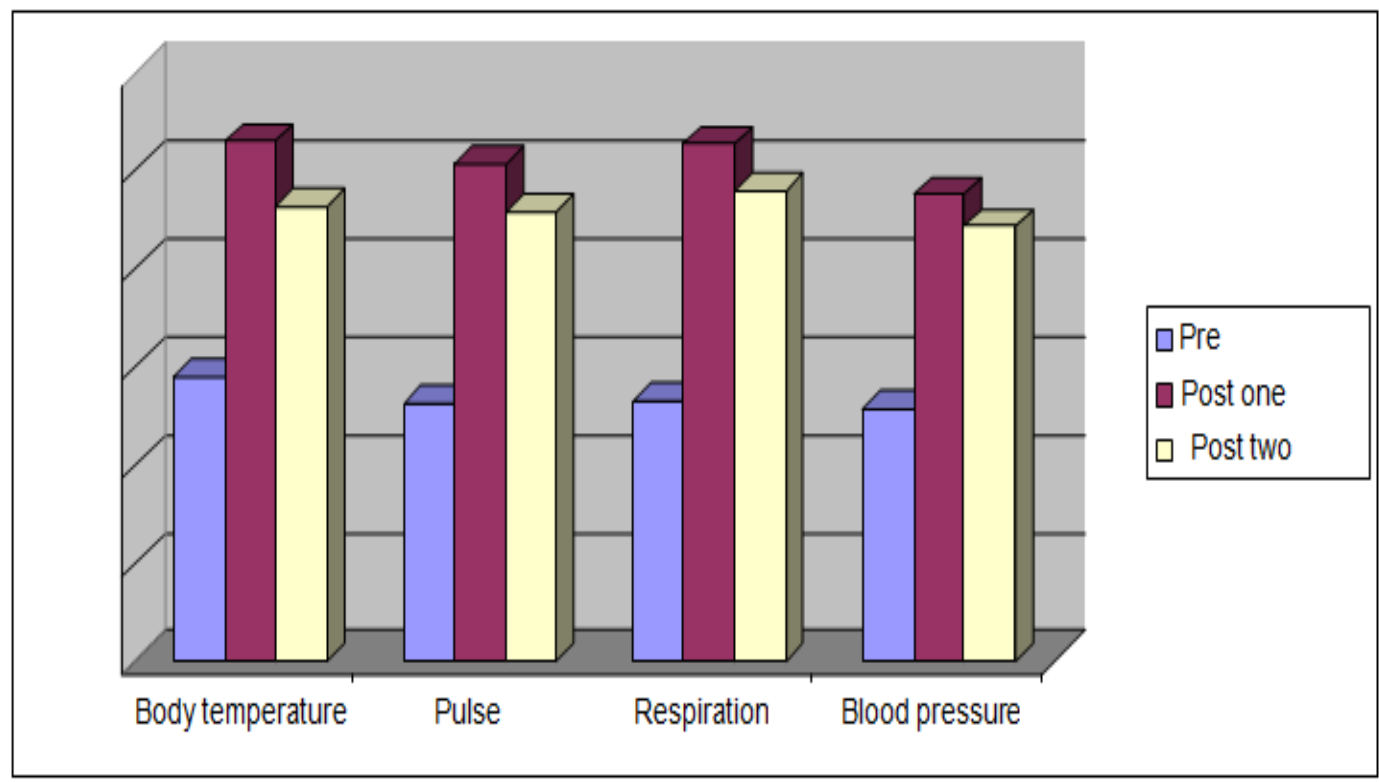

Figure (1)

Table (3) and Figure (1) illustrate increase in the post test one mean score of students' knowledge about temperature, pulse, respiration and blood pressure $(2.65 \pm 0.48,2.54 \pm 0.5,2.64 \pm .48 \& 2.38 \pm 0.69)$ respectively but slightly decreased in post test two $(2.32 \pm 0.78,2.29 \pm 0.62,2.4 \pm 0.74 \& 2.22 \pm 0.8)$ respectively. There were significant differences between pre and post tests as $(\mathrm{P}=0.000)$. While, there was no statistically significant difference between post test one and post test two related to blood pressure $(\mathrm{P}=0.140)$.

Table (4) \& Figure (2): Distribution of students according to their practices of measuring vital signs after training $\mathrm{n}=92$

\begin{tabular}{|c|c|c|c|c|c|}
\hline \multirow[b]{2}{*}{ Items } & \multicolumn{2}{|c|}{ Post test one } & \multicolumn{2}{|c|}{ Post test two } & \multirow{2}{*}{$\begin{array}{l}\text { Chi-Square } \\
\text { ( P-value) }\end{array}$} \\
\hline & No & $\%$ & No & $\%$ & \\
\hline \multicolumn{6}{|c|}{ Measuring temperature } \\
\hline Didn't do & 10 & 11.0 & 0 & 0 & \multirow{4}{*}{$\begin{array}{l}84.467 \\
(0.000)\end{array}$} \\
\hline Improper & 63 & 68.5 & 19 & 20.5 & \\
\hline Average & 19 & 20.5 & 24 & 26.2 & \\
\hline Proper & 0 & 0 & 49 & 53.3 & \\
\hline \multicolumn{6}{|c|}{ Measuring pulse } \\
\hline Didn't do & 6 & 6.5 & 0 & 0 & \multirow{4}{*}{$\begin{array}{l}79.197 \\
(0.000)\end{array}$} \\
\hline Improper & 61 & 66.3 & 17 & 18.5 & \\
\hline Average & 23 & 25.0 & 21 & 22.8 & \\
\hline Proper & 2 & 2.2 & 54 & 58.7 & \\
\hline \multicolumn{6}{|c|}{ Measuring respiration } \\
\hline Didn't do & 5 & 5.4 & 0 & 0 & \multirow{4}{*}{$\begin{array}{l}77.701 \\
(0.000)\end{array}$} \\
\hline Improper & 46 & 50.0 & 12 & 13.0 & \\
\hline Average & 36 & 39.1 & 19 & 20.7 & \\
\hline Proper & 5 & 5.4 & 61 & 66.3 & \\
\hline \multicolumn{6}{|c|}{ Measuring blood pressure } \\
\hline Didn't do & 7 & 7.6 & 0 & 0 & \multirow{4}{*}{$\begin{array}{l}71.785 \\
(0.000)\end{array}$} \\
\hline Improper & 48 & 52.2 & 8 & 8.7 & \\
\hline Average & 30 & 32.6 & 30 & 32.6 & \\
\hline Proper & 7 & 7.6 & 54 & 58.7 & \\
\hline
\end{tabular}




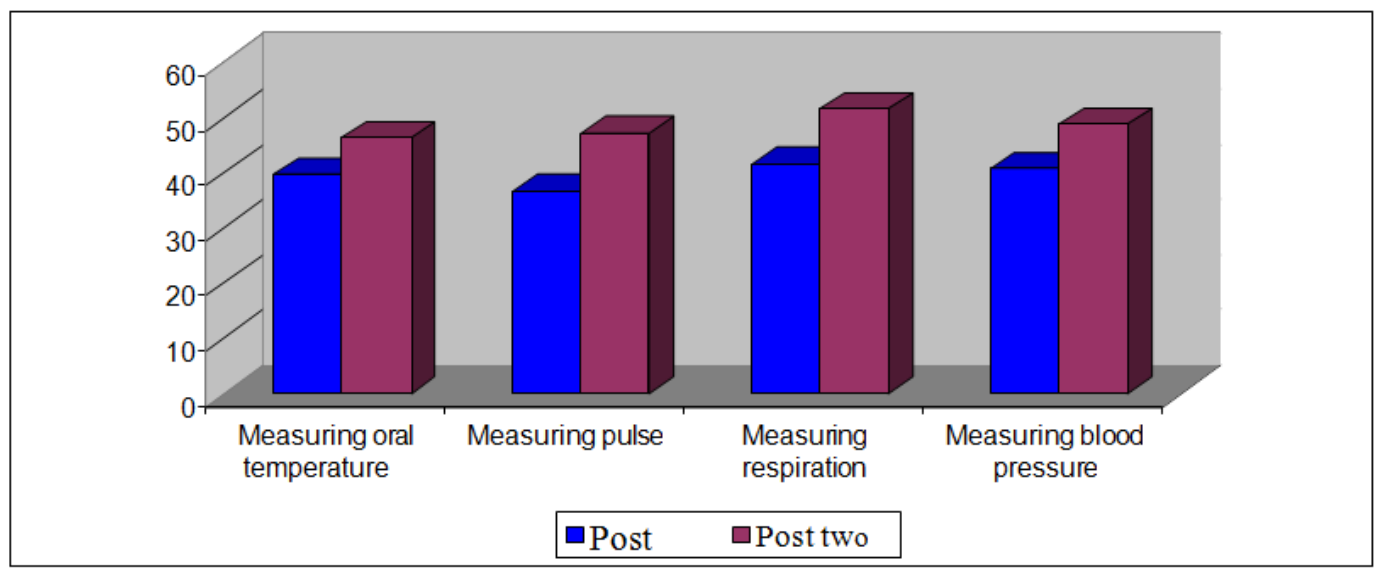

Figure (2)

Table (4) and Figure (2) demonstrate the distribution of the students according to their practices of measuring vital signs. Only $2.2 \%, 5.4 \%$ and $7.6 \%$ of them demonstrated proper measuring for pulse, respiration and blood pressure in the post test one compared to the percentages that ranged from $58.7 \%$ to $66.3 \%$ in post test two. There were statistically significant differences between post test one and post test two $(\mathrm{P}=0.000)$.

Table (5): Distribution of students according to their attitude toward training on measuring vital signs $n=92$

\begin{tabular}{|c|c|c|c|c|c|}
\hline \multirow[b]{2}{*}{ Items } & \multicolumn{2}{|l|}{ Pre } & \multicolumn{2}{|c|}{ Post } & \multirow{2}{*}{$\begin{array}{l}\text { Chi-Square } \\
\text { ( P-value) }\end{array}$} \\
\hline & No & $\%$ & No & $\%$ & \\
\hline $\begin{array}{l}\text { There are importance and benefits from training on } \\
\text { measuring vital signs }\end{array}$ & 81 & 88.0 & 91 & 98.9 & $\begin{array}{l}8.915 \\
(0.003)\end{array}$ \\
\hline \multicolumn{6}{|l|}{ Fields benefited from training } \\
\hline In the work & 63 & 77.8 & 88 & 96.7 & \multirow{2}{*}{$\begin{array}{l}14.320 \\
(0.000)\end{array}$} \\
\hline Within the family & 72 & 78.3 & 83 & 90.2 & \\
\hline $\begin{array}{l}\text { It is critical to have the skills to measure vital signs } \\
\text { and ensure that they are interpreted properly }\end{array}$ & 63 & 77.8 & 83 & 90.2 & $\begin{array}{l}4.953 \\
(0.026) \\
\end{array}$ \\
\hline
\end{tabular}

Table (5) denotes the distribution of students according to their attitude toward training on measuring vital signs. Most of them $(98.9 \%, 96.7 \%$ and $90.2 \%)$ respectively post session stated that there are importance, benefits from training on measuring vital signs, in work and within the family they added that children's health is an important issue and knowing the normal vital signs of children can help in different situations accordingly, it is critical to have the skills to measure vital signs and ensure that they are interpreted properly. There were significant differences between pre and post sessions $(\mathrm{P}=0.000)$.

\section{Discussion}

Continuing education is essential for teachers, committed to improving the health, school achievement, and well-being of students. All school teachers need to stay current in their skills and knowledge. Professional development provides opportunities for school teachers to identify areas for improvement, learn about and use proven practices, develop skills, and reflect on practice ${ }^{(14)}$.

The present study result revealed increase in the mean score of students' knowledge about temperature, pulse, respiration and blood pressure in post test one, but slightly decreased in post test two (Table 3). A study carried out on 385 subjects to identify the level of knowledge of lay people about approaching an emergency victim support the findings showed that $83.1 \%$ of the respondents recognizing the presence of vital signs, they mentioned that they knew how to do it, $90.3 \%$ of whom answered correctly about the vital signs. However, only $35.9 \%$ of those who knew how to recognize the presence of vital signs mentioned pulse and respiratory movements, while $46.6 \%$ mentioned only pulse and $5.6 \%$ only breathing ${ }^{(8,9)}$.

The present study findings demonstrated that at post test two more than half of the students were properly measuring vital signs (Table 4). In the same line, the National Open University of Nigeria, School of Sciences and Technology $(2010){ }^{(16)}$ stated that, appraisal of health status is the evaluation of the health status of school children by a variety of procedures. It is the quality of health that is assessed through the use of teachers' observations, screening tests, health history, dental inspection, medical examination and psychological test. On the other hand, Castledine $(2006){ }^{(17)}$ reported that one of the most important and commonly performed tasks, of the person assisting in medical examination, is obtaining and recording people vitals. Ass well, vital signs sometimes referred to as cardinal signs, include temperature, pulse, respiration, and blood pressure. Measuring, 
monitoring and recording a person's vital signs accurately is important as this gives an indication of the person's physiological state and provides valuable information about a resident's current health condition.

The Illinois Department of Public Health and Loyola University Medical Center (2010) ${ }^{(18)}$ constructed that during the initial assessment, the goal was simply to identify clearly abnormal vital signs suggestive of an emergent condition. It is also an important element in continuity of care if the student is referred for further medical evaluation. As well, the National Collaborating Centre for Women's and Children's Health (2007) ${ }^{(19)}$ and David McGillivray ${ }^{(20)}$ explained that in their study on "Measuring and recording temperature, heart rate, respiratory rate, and blood pressure as part of the routine assessment", abnormalities in these vital signs are known to be associated with severe illness in children. Poor accuracy of vital signs measurements has the potential to lead to unnecessary investigations. This may be worse than if no vital signs had been measured. The present study showed students' attitude, as they added that children's health is an important issue and knowing the normal vital signs of children can help in different situations accordingly, it is critical to have the skills to measure vital signs and ensure that they are interpreted properly (Table 5).

William Glasser's Choice Theory, decelerated that teachers must promote the basic needs of students. These basic needs are the requirements of survival, love and affection, freedom, leisure, and empowerment. This means that in addition to academic issues, teachers must take keen interest and help students in their physical, social, and economic status, and participate in their extracurricular activities ${ }^{(4)}$. In the same line, vital signs are useful in detecting or monitoring medical problems and it can be measured in a medical setting, or elsewhere ${ }^{(19)}$

There were no researches found that studied training teachers or faculty of education students on measuring vital signs, as all researches focused only on the role of teacher as health educator.

\section{Conclusion and Recommendations}

There were significant improvements in students' knowledge, practice and attitude related to vital signs after implementing the sessions. It was observed that there was shortage in the number of physicians and nurses working at schools. On the other side, faced with large number of schools with high density of children this can be partially supported and replaced through training the teachers on measuring vital signs as an important basic skill for all workers with children and the initial and fundamental measure in assessment that indicate any deviation from normal.

\section{Recommendation}

Study was recommended to develop a periodic training for teachers on observing and monitoring school age students to deviate normal from abnormal condition. Provide continuous awareness sessions toward measuring vital signs.

\section{Conflict of Interest}

The authors declare no conflict of interest.

\section{Acknowledgements}

The authors are thankful to all students who are participating in this study also they appreciate help provided by academic staff in Mansoura university in conduction of the study. Finally grateful thanks for person who help in publishing this study.

\section{References}

[1] Prince Henry's High School Evishlam. (2011): Job description: The role of the classroom teacher. Recruitment/JobDescClass Teach. March; pp. 1-2.

[2] Mckenzie JF, Pingeer RR, Kotecki JE. (2005): An introduction to community health. (5 ${ }^{\text {th }}$ ed.). London: Jones and Bartlett Publishers; p. 143

[3] Williamson County School District. Job description: Lead Pre-K Teacher. (2009), pp. 1-2. Accessed on 24/11/2009.

[4] Williamson County School District. (2010). Job description: Teacher - special education Printed: 21/9/2010.

[5] Cook K, Montgomery H. in Trigg E, Mohammed T. Practices in children's nursing. (2006), ( $2^{\text {nd }}$ ed.). London: Churchill Livingstone Elsevier.

[6] Royal Collage of Nursing. Standards for assessing, measuring and monitoring vital signs in infants, children and young people. RCN guidance for children's nurses and nurses working with children and young people.(2007) , p. 2.

[7] Vital signs: Measuring vital signs. (2009). A guide to help direct support professionals learn how to measure, and report vital sign measurements; Accessed on: 24/2/2009.

[8] http://www.righthealth.com/topic/Measuring_Vital_Signs\#ixzz1xxCyuCm7

[9] Pergola MA, Araujo, MEI. The layperson in emergency situations. Rev Esc Enferm USP; 42(4). (2008). 763-70.

[10] Faculty of Specific Education. Faculty Internal Regulation. Alexandria University; 2012.

[11] Faculty of Specific Education. Department of Accreditation. Electronic guideline. Zagazig University. Academic year; 2008-2009. http://edu.yorku.ca/intl/internship

[12] California Department of Developmental Services: Direct Support Professional Training Year 1and Year 2 Teacher and Student resource Guides, 2004 http://www.dds.ca.gov/DSPT/Guides.cfm 
[13] University of Oxford. (2010). Engineering science trinity term Susannah Fleming Keble College Measurement and fusion of noninvasive vital signs for routine triage of acute pediatric illness. Thesis.

[14] CDC. Adolescent and school health. How schools can implement coordinated school health Page available; December, $20,2012$.

[15] Ministry of Health and Population. $1^{\text {st }}$ year clinical book of technical schools of nursing, General Administration of Technical Health Education, 2007.

[16] National Open University of Nigeria. School of Sciences and Technology. (2010), ISBN: 978-058-661-X: 42.

[17] Castledine G. The importance of measuring and recording vital signs correctly. British Journal of Nursing, Mar; 15, (5), $2006,285$.

[18] Illinois Department of Public Health and Loyola University Medical Center Guidelines for the Nurse in the School Setting Illinois Emergency Medical Services for Children. (2010), P. 21.

[19] National Collaborating Centre for Women's and Children's Health. Feverish illness in children: assessment and initial management in children younger than 5 years. Clinical Guideline CG47, National Institute for Health and Clinical Excellence; 2007.

[20] David McGillivray. Routine vital signs not so routine: Next question? When does it matter? Pediatric Child Health. 11(4), 2006 Apr, 209. 